\title{
GMR
}

\section{Association of Beclin-1 and microRNA-30a expression with the severity and treatment response of colorectal cancer}

\author{
L. Liu*, T. Meng*, Q.S. Wang, H.Z. Jin, Z.Q. Sun, B. Jin, F. Fang and H.J. Wang \\ Department of Abdomen Surgery, \\ Cancer Hospital Affiliated to Xinjiang Medical University, Urumqi, China \\ *These authors contributed equally to this study. \\ Corresponding author: H.J. Wang \\ E-mail: wanghaijing_|@163.com \\ Genet. Mol. Res. 15 (2): gmr.15027704 \\ Received August 8, 2015 \\ Accepted November 26, 2015 \\ Published April 7, 2016 \\ DOI http://dx.doi.org/10.4238/gmr.15027704
}

ABSTRACT. We investigated the associations between Beclin-1 and microRNA-30a (miR-30a) expression and the severity and treatment response in colorectal cancer (CRC). Our sample size consisted of 139 CRC patients who were treated with surgery alone. Immunohistochemistry was used to investigate the expression and prognostic significance of Beclin-1 in CRC, while the weak expression of Beclin-1 in normal tissue was used as the basis for assessing tumors (control group). Real-time reverse transcription-polymerase chain reaction quantified miR-30a levels. The expression levels of Beclin-1 and miR-30a were associated with clinical variables and prognoses. Beclin-1 was expressed more highly in CRC tissues than in controls. This expression was related to gender $(P=0.023)$, histological grade $(P=0.006)$, $M$ stage $(P=0.004)$, tumor node metastasis stage $(P=0.020)$, vascular invasion, and nodal involvement. Patients with higher Beclin-1 expression levels had higher survival rates $(P=0.08)$ than patients with lower Beclin-1 expression levels. Beclin-1 was a prognostic indicator $(P<0.05)$ in a multivariate analysis. Beclin-1 was overexpressed in CRC tissues and was correlated with lower levels of miR-30a $(P<0.05, r$ 
$=-0.4189$ ). In conclusion, Beclin-1 was a good prognostic indicator in CRC and was correlated with survival rate. Beclin-1 is important in the growth and metastasis of CRC. Apoptosis in CRC might be due to the increased autophagy induced by decreased levels of miR-30a.

Key words: Beclin-1; MicroRNA-30a; Colorectal cancer; Autophagy; Apoptosis; Prognosis

\section{INTRODUCTION}

Colorectal cancer (CRC) is a leading cause of cancer-related tumors worldwide (Haggar and Boushey 2009). The survival rate for CRC patients 5 years after operation is very low to recurrences or metastasis (Birgisson et al., 2011). Clinical research shows that CRC patients with the same tumor node metastasis (TNM) stage have different prognoses, probably because of various molecular and genetic differences (Wan et al., 2012). Autophagy is an important cellular function that plays an important role in recycling long-lived proteins or damaged organelles (Klionsky and Emr, 2000). Under nutrient deprivation or other stressful conditions, autophagy provides essential amino acids and energy for protein synthesis to allow the organism to survive (Dunn Jr., 1994). Autophagosomes, formations of double-membrane vacuoles containing cytoplasmic constituents, are fused with lysosomes and subsequently degrade the sequestered material.

Beclin-1, a tumor susceptibility locus, was the first identified autophagy gene and is located on chromosome 17q21 (Liang et al., 1998). The autophagy effect of the Beclin-1 protein is associated with the interaction of several important cellular molecules, such as mTOR and hypoxiainducible factor-1 (Kelley et al., 2011). Previous research has shown the prognostic significance of Beclin-1 in gastric cancer (Xia et al., 2013), laryngeal squamous cell carcinoma (Huang et al., 2013), and ovarian carcinoma (Lin et al., 2013). These studies have confirmed that Beclin-1 is a useful prognostic biomarker. MicroRNA-30a (miR-30a) is involved in most cellular processes, including mRNA transcription and protein translation. Zhu et al. (2009) found that the binding sequences of miR-30a are in the Beclin-1 3'-UTR (untranslational region). The binding of miR-30a to Beclin-1 was shown to inhibit Beclin-1 expression in cancer cells.

Some studies demonstrated that in patients with rheumatoid arthritis (RA), autophagy protects cells from death by endoplasmic reticulum stress response in fibroblasts (Shin et al., 2010). This indicates that in RA, autophagy is upregulated and apoptosis is reduced.

We evaluated the prognostic value of Beclin-1 in 139 patients with $\mathrm{CRC}$ and investigated the associations between Beclin-1 and miR-30a expression and the severity and treatment response in CRC.

\section{MATERIAL AND METHODS}

\section{Patient selection}

All patients were hospitalized in the Xinjiang Medical University Cancer Hospital from January 2007 to December 2014. The patients were unrelated. The patients received no neoadjuvant chemotherapy or chemoradiotherapy before the surgical resection. The clinical variables of the CRC patients are shown in Table 1. Written approval for this study was obtained from the Xinjiang Medical University Cancer Hospital. Informed consent was obtained from all patients and control subjects. 


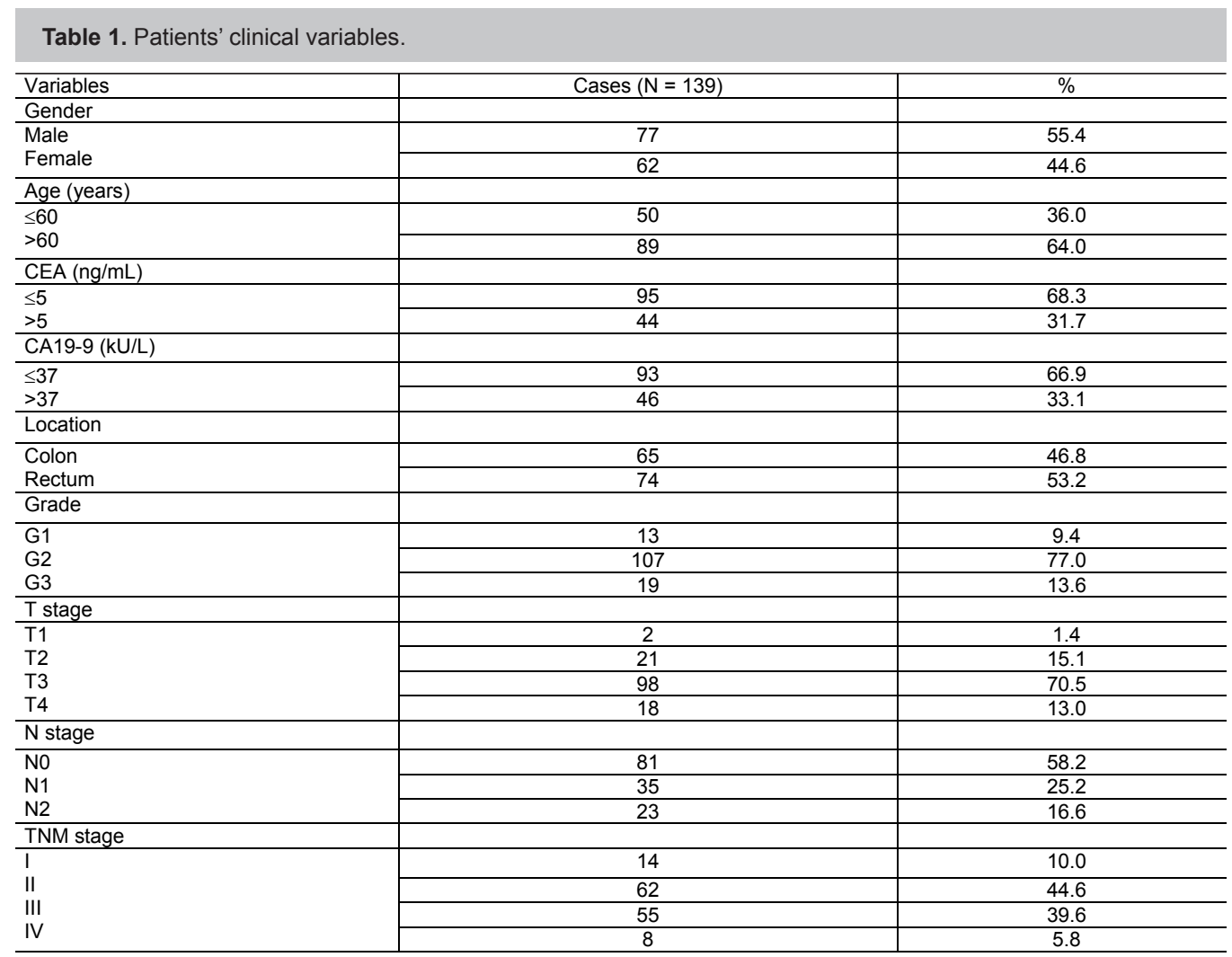

$\mathrm{CEA}=$ carcinoembryonic antigen; $\mathrm{CA}=$ carbohydrate antigen .

Total RNA extraction, stem-loop real-time polymerase chain reaction (RT-PCR), and RT-PCR

Total RNA in CRC tissue was extracted with TRIzol ${ }^{\circledR}$ Plus RNA Purification Kit (cat. 12183555, Thermo Fisher Scientific Inc., Shanghai, China) according to the manufacturer protocols. Total RNA was analyzed by electrophoresis with $1 \%$ agarose gel and the quantity was determined by the absorbance value at $260 \mathrm{~nm}\left(\mathrm{~A}_{260}\right)$. RNA was examined for optical density (OD) values at 260 and 280 $\mathrm{nm}$ and $\mathrm{OD}$ ratio $\left(\mathrm{A}_{260} / \mathrm{A}_{280}\right)$ was calculated. The selected OD ratio was between 1.7 and 2.0. A two-step RT-PCR was carried out. First-strand cDNA was synthesized from $2.5 \mu \mathrm{g}$ RNA with a PrimeScript 1st Strand cDNA Synthesis kit (cat. 6100B, Takara Biomedical Technology, Co., Ltd., Beijing, China).

Primers were designed with the Primer Premier 5 software. Primer sequences are shown in Table 2. The PCR amplification conditions and system are shown in Tables 3 and 4.

Table 2. Primer sequences, annealing temperatures, and lengths.

\begin{tabular}{l|l|c|c}
\hline Name & Primer sequence (5'-3') & Length $(\mathrm{bp})$ & Annealing temperature $\left({ }^{\circ} \mathrm{C}\right)$ \\
\hline \multirow{2}{*}{ Beclin-1 } & F: GGATGGATGTGGAGAAAGGAAG & 152 & 58 \\
\cline { 2 - 2 } & R: TGAGGACACCCAAGCAAGACC & & 61 \\
\cline { 2 - 2 } & F: ATCGTGCGTGACATTAAGGAGAAG & 179 & \\
\hline
\end{tabular}

$\mathrm{F}$ : forward primer; R: reverse primer. 
Table 3. PCR amplification conditions.

\begin{tabular}{l|l|l|l}
\hline Step & Temperature $\left({ }^{\circ} \mathrm{C}\right)$ & Time & Cycle number \\
\hline Predegeneration & 95 & $5 \mathrm{~min}$ & \\
\hline Degeneration & 95 & $30 \mathrm{~s}$ & \multirow{2}{*}{40 cycles } \\
\cline { 1 - 2 } Annealing & $58-61$ & $30 \mathrm{~s}$ & \\
\cline { 1 - 3 } Extension & 72 & $1 \mathrm{~min}$ & 1 cycle \\
\cline { 1 - 2 } Extension terminal & 72 & $30 \mathrm{~min}$ & \\
\hline Storage & 4 & $\rightarrow \infty$ & \\
\hline
\end{tabular}

Table 4. PCR amplification system $(20-\mu \mathrm{L}$ reaction).

\begin{tabular}{l|c}
\hline Composition & Volume $(\mu \mathrm{L})$ \\
\hline Ultrapure water & 7 \\
\hline 2X PCR Mix & 10 \\
\hline Primer F & 1 \\
\hline Primer R & 1 \\
\hline Template cDNA & 1 \\
\hline Total volume & 20 \\
\hline
\end{tabular}

The amplicons were analyzed by electrophoresis on a $1 \%$ agarose gel. The sequence detector system software, PE Applied Biosystems (Thermo) was used for data analysis. The delta delta Ct method was used for quantification with $\beta$-actin as the internal reference.

The expression of miR-30a was determined by stem-loop RT-PCR with U6 small nuclear RNA as the internal reference. The stem-loop RT primers were designed by Shanghai GenePharma Co., Ltd. (China).

\section{Western blot}

Tissue samples from CRC patients were homogenized with sodium dodecyl sulfate lysis buffer (P0013G, Beyotime, Shanghai, China) and a protease inhibitor cocktail (cat. 554779, Becton, Dickinson and Company, Shanghai, China) according to the specifications. Tissue homogenates were then centrifuged at $12,000 \mathrm{~g}$ for $10 \mathrm{~min}$ at $4^{\circ} \mathrm{C}$. The protein quality was determined by Coomassie brilliant blue (cat. 0472-10G, Amresco, Shanghai, China) staining and the concentration was determined by the bicinchoninic acid method (cat. P0010s, Beyotime). The protein samples were separated by SDS-polyacrylamide gel electrophoresis with a $5 \%$ stacking gel and $10 \%$ separating gel and transferred to polyvinylidene fluoride membranes (Millipore Corporate, Billerica, MA, USA). The membranes were then blocked with Tris-buffered saline (TBS) containing $0.05 \%$ Tween-20 (TBST) and 5\% non-fat milk for $1 \mathrm{~h}$ at $25^{\circ} \mathrm{C}$. Rabbit polyclonal anti-Beclin-1 (1:200, sc-11427, Santa Cruz Biotechnology, Inc., Shanghai, China) and mouse monoclonal anti- $\beta$-actin (1:200, sc-47778, Santa Cruz Biotechnology, Inc.) were added to incubate at $4^{\circ} \mathrm{C}$ overnight. After washing with TBST, goat anti-rabbit (1:3000, cat. 111-035-003, Jackson ImmunoResearch Inc.) and goat anti-mouse (1:3000, cat. 115-035-003, Jackson ImmunoResearch Inc.) were added to the membranes and incubated for $1 \mathrm{~h}$ at room temperature. After washing with TBST, the membranes were developed by electrochemiluminescence and the western blot detection system.

\section{Immunohistochemistry (IHC)}

All tissues were cut into $3-\mathrm{mm}^{3}$ cubes and then cut into $3-\mu \mathrm{m}$ sections. After incubation at 
$60^{\circ} \mathrm{C}$ for adhesion, the sections were dewaxed and rehydrated in graded alcohol solutions $(100 \%$ for $10 \mathrm{~min}, 95 \%$ for $5 \mathrm{~min}, 90 \%$ for $5 \mathrm{~min}, 80 \%$ for $5 \mathrm{~min}, 75 \%$ for $5 \mathrm{~min}, 70 \%$ for $5 \mathrm{~min}$ ), then placed in citrate buffer (1:10 dilution, pH 6.0) for antigen unmasking and heated at $120^{\circ} \mathrm{C}$ for $5 \mathrm{~min}$ a total of three times. After cooling to room temperature, the sections were incubated in hydrogen peroxide for $10 \mathrm{~min}$, then incubated in bovine serum albumin for $10 \mathrm{~min}$. Rabbit polyclonal antibody against Beclin-1 (1:100, sc-11427, Santa Cruz Biotechnology, Inc.) was added to the sections and incubated overnight at $4^{\circ} \mathrm{C}$ in a humidified chamber. The next day, the sections were incubated in secondary antibody (1:100, sc-2027, Santa Cruz Biotechnology, Inc.) for $30 \mathrm{~min}$ at room temperature after washing with PBS three times for $7 \mathrm{~min}$ each time. The sections were processed using a Vectastain ABC-AP kit for another 30 min (VEctor, Burlingame, CA, USA). The sections were washed three times with PBS for 7 min each time, then incubated with 3,3'-diaminobenzidine substrate for $5 \mathrm{~min}$, counterstained with hematoxylin, dehydrated, and mounted.

Normal rabbit immunoglobulin $G$ was substituted for primary antibody as the negative control.

\section{Assessment of Beclin-1 expression}

A semi-quantitative analysis was used to evaluate the expression of Beclin-1, which is expressed in both the nuclei and cytoplasm of cancer cells. The percentage of cells with positive nuclei was recorded in all available optical fields (X200 magnification). The mean value was used to score and group cases into two categories of the low ( $<$ mean) and the high ( $\geq$ mean).

\section{Clinical follow-up}

All the patients were followed-up every 3 months after surgical resection. The survival rate was recorded.

\section{Statistical analysis}

All the data were analyzed by the SPSS 17.0 software (Chicago, IL, USA). The correlation between Beclin-1 expression levels and clinical variables in CRC patients was analyzed by a chisquare test. A t-test was used to assess the PCR results. A Cox proportional hazard regression model was used to identify independent prognostic factors. A value of $\mathrm{P}<0.05$ was considered significant.

\section{RESULTS}

\section{Expression levels of miR-30a decrease in CRC patients}

We used RT-PCR to analyze the relationship between miR-30a and Beclin-1 expression in CRC tissues. The delta delta $\mathrm{Ct}$ method was used for the quantitative analysis of RT-PCR. The results showed that miR-30a expression levels were significantly lower in CRC tissues $(P<0.05)$ than in normal tissues. Levels of miR-30a were inversely correlated with Beclin-1 mRNA levels ( $P$ $<0.05, r=-0.4189$ ).

\section{Correlation between Beclin-1 expression and clinical variables in CRC patients}

Higher Beclin-1 expression was found in 54.0\% (75/139) of patients with CRC, while lower 
expression levels were observed in 46.0\% (64/139) of patients. The results of the chi-square test showed that Beclin-1 expression was significantly correlated with gender $(P=0.023)$, histological grade $(P=0.006)$, $M$ stage $(P=0.004)$, TNM stage $(P=0.020)$, vascular invasion, and nodal involvement. However, there were no significant correlations between Beclin-1 expression and other clinical variables including age, tumor location, T stage, and $\mathrm{N}$ stage (Table 5).

By testing prognostic factors of patient survival, we found that high Beclin-1 expression was a prognostic factor for $C R C$ patients $(P<0.006)$ that was independent of tumor location, gender, and histological differentiation.

\begin{tabular}{|c|c|c|c|c|}
\hline \multirow[t]{2}{*}{ Variables } & \multirow[t]{2}{*}{ Cases $(\mathrm{N}=139)$} & \multicolumn{2}{|c|}{ Beclin-1 mRNA level } & \multirow[t]{2}{*}{$P$} \\
\hline & & High $(\mathrm{N}=75)$ & Low $(\mathrm{N}=64)$ & \\
\hline \multicolumn{5}{|l|}{ Gender } \\
\hline \multirow{2}{*}{$\begin{array}{l}\text { Male } \\
\text { Female }\end{array}$} & 77 & 26 & 40 & \multirow[t]{2}{*}{$0.023^{\star}$} \\
\hline & 62 & 49 & 24 & \\
\hline \multicolumn{5}{|c|}{ Age (years) } \\
\hline$\leq 60$ & 50 & 30 & 32 & \multirow[t]{2}{*}{0.246} \\
\hline$>60$ & 89 & 45 & 32 & \\
\hline \multicolumn{5}{|c|}{ CEA (ng/mL) } \\
\hline$\leq 5$ & 95 & 45 & 37 & \multirow[t]{2}{*}{0.550} \\
\hline$>5$ & 44 & 30 & 27 & \\
\hline \multicolumn{5}{|c|}{ CA19-9 (kU/L) } \\
\hline$\leq 37$ & 93 & 48 & 39 & \multirow[t]{2}{*}{0.791} \\
\hline$>37$ & 46 & 27 & 25 & \\
\hline \multicolumn{5}{|l|}{ Location } \\
\hline Colon & 65 & 31 & 29 & \multirow[t]{2}{*}{0.398} \\
\hline Rectum & 74 & 44 & 35 & \\
\hline \multicolumn{5}{|l|}{ Grade } \\
\hline G1 & 13 & 6 & 5 & \multirow[t]{3}{*}{$0.006^{*}$} \\
\hline G2 & 107 & 62 & 43 & \\
\hline G3 & 19 & 7 & 16 & \\
\hline \multicolumn{5}{|l|}{ T stage } \\
\hline $\mathrm{T} 1$ & 2 & 2 & 1 & \multirow[t]{4}{*}{0.856} \\
\hline $\mathrm{T} 2$ & 21 & 10 & 8 & \\
\hline T3 & 98 & 54 & 45 & \\
\hline $\mathrm{T} 4$ & 18 & 9 & 10 & \\
\hline \multicolumn{5}{|l|}{$\mathrm{N}$ stage } \\
\hline No & 81 & 48 & 35 & \multirow[t]{3}{*}{0.401} \\
\hline N1 & 35 & 20 & 17 & \\
\hline $\mathrm{N} 2$ & 23 & 7 & 12 & \\
\hline \multicolumn{5}{|l|}{ M stage } \\
\hline MO & 126 & 69 & 54 & \multirow[t]{2}{*}{$0.004^{*}$} \\
\hline M1 & 13 & 6 & 10 & \\
\hline \multicolumn{5}{|c|}{ TNM stage } \\
\hline I & 14 & 12 & 6 & \multirow{4}{*}{$0.020^{*}$} \\
\hline II & 62 & 31 & 23 & \\
\hline III & 55 & 26 & 19 & \\
\hline IV & 8 & 6 & 16 & \\
\hline
\end{tabular}

\section{Survival analysis}

The mean survival time was 85.6 months $(95 \% \mathrm{Cl}: 80.3 \pm 90.9)$. Patients with higher Beclin-1 expression levels had higher survival rates $(P=0.08)$ than patients with lower Beclin-1 expression levels. The mean survival time for patients with high Beclin-1 expression was 90.2 months (95\% Cl: $84.4 \pm 96.0)$. The mean survival time for patients with low Beclin-1 expression was 83.1 months (95\% Cl: $76.0 \pm 90.2)$. 


\section{DISCUSSION}

Autophagy plays an important role in clinical outcomes of human malignancies and has a dual function in tumor development. Autophagy either acts as a tumor suppressor or promotes tumor proliferation in different cancers. Most research has focused on Beclin-1 as the essential protein involved in the initiation of autophagosome formation (Cao and Klionsky, 2007). However, the role of autophagy in clinical outcomes of human malignancies is still unclear and controversial. Beclin-1 was proved to be the mammalian ortholog of the yeast Apg6/Vps30 gene (Cao and Klionsky, 2007). The main function of Beclin-1 is as a scaffold for the formation of the phosphatidylinositol 3-kinase (PI3K) complex, one of the first components involved in developing the autophagosome that is essential in autophagy. The overexpression of Beclin-1, which has been reported to reside in the trans-Golgi network, endoplasmic reticulum, and mitochondria (Kihara et al., 2001; Cao and Klionsky, 2007), is very common in carcinomas. Li et al. (2009) found that high Beclin-1 expression was linked to better prognoses in patients with stage III colorectal cancer.

In our study, we quantified Beclin-1 expression by RT-PCR, western blot, and IHC, and found that $54.0 \%$ (75/139) of CRC patients had increased levels of Beclin-1 expression that could be detected in the membrane-plasma, cytoplasm, and nucleus of CRC tissues. Beclin-1 expression in CRC patients was correlated with gender, histological grade, $M$ stage, and TNM stage. By analyzing the correlations between Beclin-1 expression and clinical variables, we found that high Beclin-1 expression was a positive prognostic factor for CRC independent of gender, age, T stage, and tumor location.

Existing evidence focused on the prognostic role of Beclin-1 in human carcinomas is rare and contradictory. According to Ahn et al. (2007), Beclin-1 is poorly expressed in normal colon and gastric mucosa. However, the most prominent expression pattern in tumor cells of hepatocellular carcinomas show that Beclin-1 is not expressed (Ding et al., 2008). Beclin-1 was downregulated in breast cancer tissues comparing to normal breast tissues, indicating decreased autophagy in breast tumor development (Liang et al., 1999). Qu et al. (2003) found common allelic deletions of Beclin-1 in breast cancer cells, leading to promoted tumor generation. Similarly to previous research (Li et al., 2009), we also found lower expression of Beclin-1 in normal tissues adjacent to CRC tissues. Studies have shown that Beclin-1 was deleted in about $75 \%$ of ovarian cancers, $50 \%$ of breast cancers, and $40 \%$ of prostate cancers (Aita et al., 1999). However, in colon and gastric cancers, Beclin-1 expression and autophagy increased compared to normal tissues (Ahn et al., 2007; Li et al., 2009), indicating the specificity of Beclin-1 in different organs and carcinomas. According to some reports (Ding et al., 2008; Chen et al., 2009; Kim et al., 2011; Roesly et al., 2012; Geng et al., 2012; Lin et al., 2013), higher Beclin-1 expression is associated with a better prognosis. Our results coincide with this finding.

An inhibitor of Beclin-1, miR-30a, plays an important role in most cellular processes, including mRNA transcription and protein translation. A previous study found that miR-30a inhibited Beclin-1 expression by binding the sequences in the 3'-UTR of Beclin-1 (Zhu et al., 2009). We found that miR-30a levels decreased in CRC tissues while Beclin-1 levels increased. This phenomenon indicated that autophagy increased in CRC tissues, which could be induced by miR-30a decrease.

Molecular alteration would affect the biological processes mediating how tumor genesis cells respond to the environment (Lao et al., 2013). CRC patients in TNM II stage and III stage need surgical resection combined with post-operative adjuvant chemotherapy. However, 30-40\% of those patients lose their battle against CRC after therapies (Lao et al., 2013). CRC recurrences usually happen in 5 years and patients with recurrences have poor responses towards proposed 
post-operative adjuvant chemotherapy. Therefore, we need better prognostic markers that can predict the treatment outcome for CRC patients to avoid both under- and over-treatment.

In conclusion, we evaluated the relationship between Beclin-1 expression and survival in different stages of CRC patients. Beclin-1 was correlated with survival and is important in growth and metastasis of CRC. The high expression of Beclin-1 in CRC was a favorable prognostic indicator for survival and prognosis, and the sensitivity and specificity of Beclin-1 in CRC would increase as the TNM staging. Lastly, our results suggest that apoptosis in CRC might be due to increased autophagy induced by lower levels of miR-30a.

\section{Conflicts of interest}

The authors declare no conflict of interest

\section{ACKNOWLEDGMENTS}

Research supported by the Cancer Hospital Affiliated to Xinjiang Medical University.

\section{REFERENCES}

Ahn $\mathrm{CH}$, Jeong EG, Lee JW, Kim MS, et al. (2007). Expression of beclin-1, an autophagy-related protein, in gastric and colorectal cancers. APMIS 115: 1344-1349. http://dx.doi.org/10.1111/j.1600-0463.2007.00858.x

Aita VM, Liang XH, Murty VV, Pincus DL, et al. (1999). Cloning and genomic organization of beclin 1, a candidate tumor suppressor gene on chromosome 17q21. Genomics 59: 59-65. http://dx.doi.org/10.1006/geno.1999.5851

Birgisson H, Wallin U, Holmberg L and Glimelius B (2011). Survival endpoints in colorectal cancer and the effect of second primary other cancer on disease free survival. BMC Cancer 11: 438. http://dx.doi.org/10.1186/1471-2407-11-438

Cao Y and Klionsky DJ (2007). Physiological functions of Atg6/Beclin 1: a unique autophagy-related protein. Cell Res. 17: 839849. http://dx.doi.org/10.1038/cr.2007.78

Chen Y, Lu Y, Lu C and Zhang L (2009). Beclin-1 expression is a predictor of clinical outcome in patients with esophageal squamous cell carcinoma and correlated to hypoxia-inducible factor (HIF)-1alpha expression. Pathol. Oncol. Res. 15: 487-493. http://dx.doi.org/10.1007/s12253-008-9143-8

Ding ZB, Shi YH, Zhou J, Qiu SJ, et al. (2008). Association of autophagy defect with a malignant phenotype and poor prognosis of hepatocellular carcinoma. Cancer Res. 68: 9167-9175. http://dx.doi.org/10.1158/0008-5472.CAN-08-1573

Dunn WA Jr (1994). Autophagy and related mechanisms of lysosome-mediated protein degradation. Trends Cell Biol. 4: 139143. http://dx.doi.org/10.1016/0962-8924(94)90069-8

Geng QR, Xu DZ, He LJ, Lu JB, et al. (2012). Beclin-1 expression is a significant predictor of survival in patients with lymph node-positive gastric cancer. PLoS One 7: e45968. http://dx.doi.org/10.1371/journal.pone.0045968

Haggar FA and Boushey RP (2009). Colorectal cancer epidemiology: incidence, mortality, survival, and risk factors. Clin. Colon Rectal Surg. 22: 191-197. http://dx.doi.org/10.1055/s-0029-1242458

Huang L, Wang S, Li SS and Yang XM (2013). Prognostic significance of Beclin-1 expression in laryngeal squamous cell carcinoma. Pathol. Oncol. Res. 19: 771-777. http://dx.doi.org/10.1007/s12253-013-9642-0

Kelley RK, Wang G and Venook AP (2011). Biomarker use in colorectal cancer therapy. J. Natl. Compr. Canc. Netw. 9: 1293-1302. Kihara A, Kabeya Y, Ohsumi Y and Yoshimori T (2001). Beclin-phosphatidylinositol 3-kinase complex functions at the transGolgi network. EMBO Rep. 2: 330-335. http://dx.doi.org/10.1093/embo-reports/kve061

Kim HS, Lee SH, Do SI, Lim SJ, et al. (2011). Clinicopathologic correlation of beclin-1 expression in pancreatic ductal adenocarcinoma. Pathol. Res. Pract. 207: 247-252. http://dx.doi.org/10.1016/j.prp.2011.02.007

Klionsky DJ and Emr SD (2000). Autophagy as a regulated pathway of cellular degradation. Science 290: 1717-1721. http:// dx.doi.org/10.1126/science.290.5497.1717

Lao VV, Welcsh P, Luo Y, Carter KT, et al. (2013). Altered RECQ Helicase Expression in Sporadic Primary Colorectal Cancers. Transl. Oncol. 6: 458-469. http://dx.doi.org/10.1593/tlo.13238

Li BX, Li CY, Peng RQ, Wu XJ, et al. (2009). The expression of beclin 1 is associated with favorable prognosis in stage IIIB colon cancers. Autophagy 5: 303-306. http://dx.doi.org/10.4161/auto.5.3.7491 
Liang XH, Kleeman LK, Jiang HH, Gordon G, et al. (1998). Protection against fatal Sindbis virus encephalitis by beclin, a novel Bcl-2-interacting protein. J. Virol. 72: 8586-8596.

Liang XH, Jackson S, Seaman M, Brown K, et al. (1999). Induction of autophagy and inhibition of tumorigenesis by beclin 1. Nature 402: 672-676. http://dx.doi.org/10.1038/45257

Lin HX, Qiu HJ, Zeng F, Rao HL, et al. (2013). Decreased expression of Beclin 1 correlates closely with Bcl-xL expression and poor prognosis of ovarian carcinoma. PLoS One 8: e60516. http://dx.doi.org/10.1371/journal.pone.0060516

Qu X, Yu J, Bhagat G, Furuya N, et al. (2003). Promotion of tumorigenesis by heterozygous disruption of the beclin 1 autophagy gene. J. Clin. Invest. 112: 1809-1820. http://dx.doi.org/10.1172/JCI20039

Roesly HB, Khan MR, Chen HD, Hill KA, et al. (2012). The decreased expression of Beclin-1 correlates with progression to esophageal adenocarcinoma: the role of deoxycholic acid. Am. J. Physiol. Gastrointest. Liver Physiol. 302: G864-G872. http://dx.doi.org/10.1152/ajpgi.00340.2011

Shin YJ, Han SH, Kim DS, Lee GH, et al. (2010). Autophagy induction and CHOP under-expression promotes survival of fibroblasts from rheumatoid arthritis patients under endoplasmic reticulum stress. Arthritis Res. Ther. 12: R19. http:// dx.doi.org/10.1186/ar2921

Wan XB, Zhao Y, Fan XJ, Cai HM, et al. (2012). Molecular prognostic prediction for locally advanced nasopharyngeal carcinoma by support vector machine integrated approach. PLoS One 7: e31989. http://dx.doi.org/10.1371/journal.pone.0031989

Xia P, Wang JJ, Zhao BB and Song CL (2013). The role of beclin-1 expression in patients with gastric cancer: a meta-analysis. Tumour Biol. 34: 3303-3307. http://dx.doi.org/10.1007/s13277-013-1049-8

Zhu H, Wu H, Liu X, Li B, et al. (2009). Regulation of autophagy by a beclin 1-targeted microRNA, miR-30a, in cancer cells. Autophagy 5: 816-823. http://dx.doi.org/10.4161/auto.9064 